\title{
A Layout Investigation of Large Wind Farm in Akhfennir using Real Coded Genetic Algorithm
}

\author{
Mohammed Amine Hassoine ${ }^{1}$, Fouad Lahlou ${ }^{2}$, Adnane Addaim ${ }^{3}$, Abdessalam Ait Madi ${ }^{4}$ \\ romema@yahoo.fr' ${ }^{1}$, lahloufouad@ hotmail.com², adnane.addaim@uit.ac.ma ${ }^{3}$, \\ abdessalam.aitmadi@uit.ac.ma ${ }^{4}$ \\ Faculty of Sciences ${ }^{1,2}$, National School of Applied Sciences ${ }^{3,4}$, Ibn Tofail University, 14000 \\ Kénitra, Morocco
}

\begin{abstract}
The objective of this study is to evaluate the effect of wind turbine spacing in large wind farm on the total energy loss of the wind farm, the power loss is due to the wake effect between wind turbines, on a site gathering several wind turbines, if the wind turbines are too close, the loss of power increases with the wake effect. This paper presents an investigation into optimal wind farm layout in 88 wind farm configurations of a hypothetical WF in Tarfaya, to search the optimal number of Wind Turbines (WTs), the wind farm are Installed on an area of $35 \mathrm{~km} 2(7000 \mathrm{~m} \times 5000 \mathrm{~m})$, with the aim to maximize the electrical power generated by all WTs and grows the annual economic profitability of the $\mathrm{WF}$, in order to approve the result of this investigation a new approach based on the division of the wind farm in the sub domain method is proposed, to search the optimal location of Wind Turbines by mean an RCGA (Real Coded Genetic Algorithm). This new proposed approach is promising in terms of the applicability in large wind farm. It is also more suitable when performing the wind farm layout assessment in WPP (Wind Power Project).
\end{abstract}

Keywords: Wind Farm, Power, layout, Optimization, Cost, Energy, RCGA, Genetic Algorithm.

\section{Introduction}

The development of wind farms (WFs) requires optimal placement of the wind turbines (WTs) in relation to each other in order to maximize the production of the wind farm. If the turbines are too close, the wake effects prevent to provide the full power If they are too far away, the wind resource is not exploited optimally. The wake power losses currently measured in the wind farm can reach 20\% [1]. Thus, optimizing the placement of wind turbines becomes a real challenge. The selection of an appropriate site is essential to the success of a wind farm (WF) project it plays a crucial role in financial returns, a good arrangement of wind turbines in a wind farm can improve the performance of the wind farm (WF). Many studies have been carried out by different researchers to evaluate the effects of wind turbine spacing (WTS) on the performance of the wind farm [2], [3], [4],[5], along and across the prevailing wind direction by varying wind turbine spacing in prevailing wind direction (PWD) and crosswind direction (CWD), the wind turbine spacing was expressed as a multiple of the rotor diameter of wind turbine. Mosetti et al. [2] modeled an wind farm of $2 \mathrm{~km} \times 2 \mathrm{~km}$ by 5D in CWD and 5D in PWD, Archer et al. [3] studied The most efficient arrangement of the Lillgrund offshore wind farm, close to Sweden, which includes 48 turbines with six different configurations, 3.2D to 6.4D in CWD and 4.3D to 8.6D in PWD, Gao et al. [4] investigated the potential for offshore wind farm by 5D to 15D along the PWD and 5D to 12D in CWD, García et al. [5] conducted an experimental wind tunnel (1D to 18D) and concluded in the distance between 6D and 15D, the wake shows a similar profile of velocity behind the WT. In this work, we investigated regular layout and irregular layout of wind turbines within a large wind farm. In order to perform this investigation, we consider a hypothetical large wind farm $(7000 \mathrm{~m} \times 5000 \mathrm{~m})$ under 88 configurations witch the number of wind turbines is varied between 30 and 176 and arranged in regular layout, wind turbines were separated by 5D to 15D along the PWD and 5D to $12 \mathrm{D}$ in CWD. The best regular layout is achieved by comparing the ratio of cost per total power generation for each configuration. With the aim to find the best irregular layout of large wind farm in-terms of minimum unit cost of energy produce, we proposed a new method based on the division of the large wind farm (LWF )in the sub domain, to search the optimal location in irregular layout of Wind Turbines by mean an RCGA (Real Coded Genetic Algorithm). 
The organization of this paper is presented as follows. Section 2 presents a brief presentation of the wind farms model. Section 3 gives the optimization method. The results and their interpretations are discussed in section 4 . The conclusion of this proposed work is given in section 5 .

\section{MODELS OF WIND FARM}

\subsection{Wind farm Site location and Data Source description}

The Figure 1-(a) gives a map of the Tarfaya territory. Tarfaya is a Moroccan coastal town. It is located at the edge of the Atlantic Ocean, about $890 \mathrm{~km}$ southwest of the capital Rabat, $100 \mathrm{~km}$ north-north-east of Laayoune. Its latitude and longitude Coordinates are respectively $27^{\circ} 54^{\prime} 48^{\prime \prime} \mathrm{N}$ and $12^{\circ} 55^{\prime} 54^{\prime \prime} \mathrm{W}$. For most of the year, the wind blows so hard in Tarfaya city. Consequently is known for its innovative economic projects, such as that of the largest park in Africa, called the Tarfaya wind farm (Akhfennir WF). As seen in Figure 1-(b), the location of a hypothetical WF is selected near of the Tarfaya WF. The lifetime of an wind farm is assumed to be 20 years [6], the wind data of twenty years (1998-2018), which are used here, are extracted from the MERRA-2 [7], [8].

b

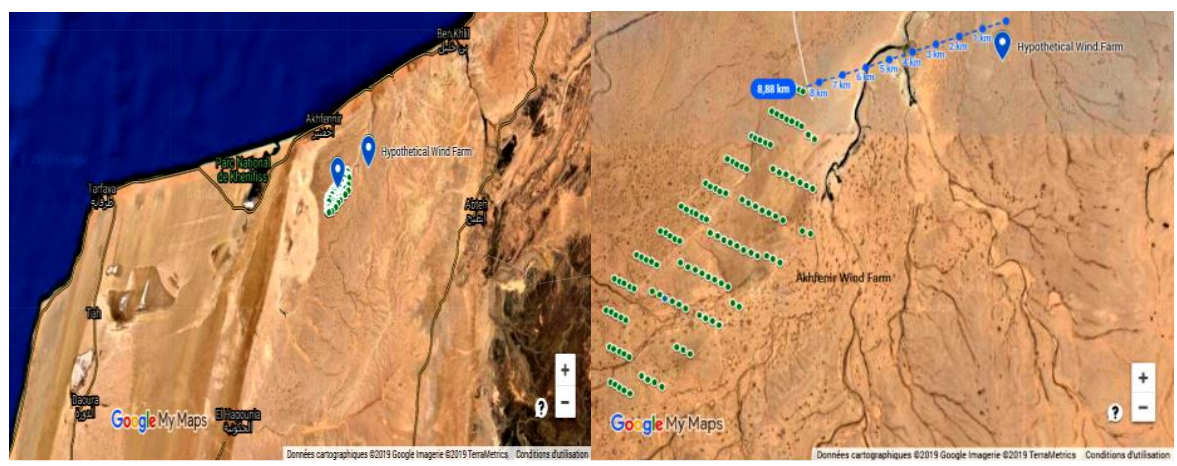

Fig. 1. Tarfaya territory map and location of the hypothetical wind farm: (a) Tarfaya territory map; (b) Akhfennir wind farm layout (117 WTs) and hypothetical wind farm.

Table 1 shows latitude and longitude coordinates of MERRA-2 point and those of Tarfaya WF and hypothetical WF.

Table 1. MERRA-2 grid point, Akhfennir wind farm and hypothetical wind farm coordinates.

\begin{tabular}{lll}
\hline Reference & Latitude N & Longitude W \\
\hline $\begin{array}{l}\text { Akhfennir WF } \\
\begin{array}{l}\text { Tarfaya } \\
\text { hypothetical WF }\end{array}\end{array}$ & $27^{\circ} 57^{\circ} 3.956^{\prime \prime} \mathrm{N}$ & $11^{\circ} 59^{\prime} 52.058^{\prime \prime} \mathrm{W}$ \\
MERRA-2 & $28^{\circ} \mathrm{N}$ & $11^{\circ} 52^{\prime} 29.999^{\prime} \mathrm{W}$ \\
\hline
\end{tabular}

\subsection{Wind Characteristics and Analytical Model}

Weibull distribution and Cumulative distribution function are been used to express the wind speed frequency distribution. We used here graphic method [9] in which Weibull parameters have been estimated by using linear LSM (Least-Squares regression Method) [19] with regress variable taken as wind speed to compute the best fitted line. The hourly wind speed is extrapolated to the hub height of the wind turbines by using the power law. Here we use the hourly wind data (20 years) from the MERRA-2 point. Figure 2-(a) shows the hourly mean wind speed at MERRA-2 site A (Tarfaya hypothetical WF) over the last twenty years at 80 meters, with an average of $7.37 \mathrm{~m} / \mathrm{s}$ indicated by the green line. Figure 2-(b) shows Wind speeds distributions at $80 \mathrm{~m}$ above ground and the Weibull distributions of Tarfaya 
hypothetical WF. the Plot of twice logarithm of Cumulative distribution function should yield a straight line. The gradient of the line is $\mathrm{k}$ (shape parameter) and the intercept with the $\mathrm{y}$-axis is - $\mathrm{k} \ln$ (c) [10], Figure 3-(a) shows the numerically linearized data of twice logarithm of Cumulative distribution function and graphically data. The values of shape parameter $k$ and scale parameter $c$ (obtained graphically) are nearly similar to the numerical. In order to give a view of how wind speed and direction are distributed. The wind rose are used to find the prevailing wind direction in location of Tarfaya hypothetical WF site. Predominant wind direction in this region is calculated over a 20-year period (1998-2018), which shows that the wind direction is predominately generated from the ENE (East North-East) and E (East), See Figure 3-(b).

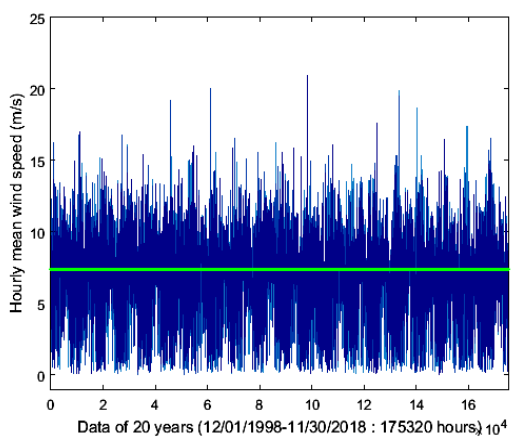

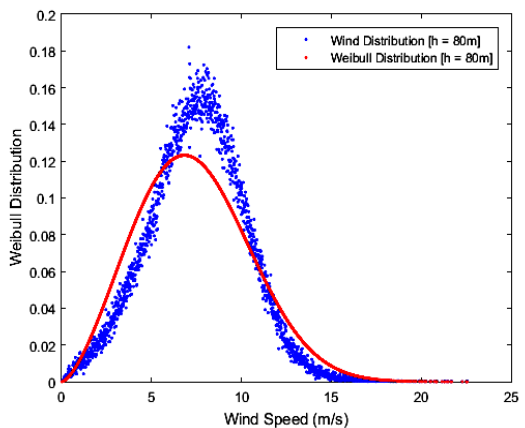

Fig. 2. Wind Characteristics: (a) Wind data in the Site A, from 1998 to 2018; (b) Wind speeds distributions at $80 \mathrm{~m}$ and the Weibull distributions of Tarfaya hypothetical WF

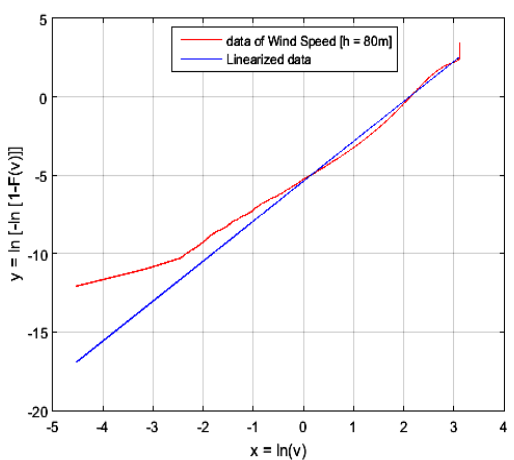

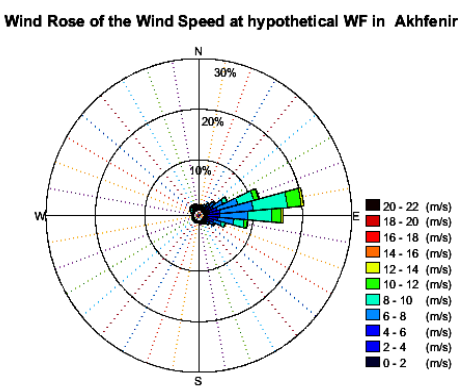

Fig. 3. Wind Characteristics: (a) linearized data; (b) Wind rose of wind speed at hypothetical WF.

The weibull parameters and mean speed are represented in Table 2.

Table 2. Weibull parameters and mean speed.

\begin{tabular}{lllll}
\hline Site & Hub & Weibull & Weibull & $\begin{array}{l}\text { Mean } \\
\text { speed }(\mathrm{m} / \mathrm{s})\end{array}$ \\
& Height $(\mathrm{m})$ & $\mathrm{K}$ & $\mathrm{C}$ & 6.8452 \\
MERRA-2 & 50 & 2.5452 & 7.7114 & 7.3798 \\
Tarfaya & 80 & 2.5452 & 8.3137 & \\
HWF & & & & \\
\hline
\end{tabular}




\subsection{Wake effect model}

When wind flows through the rotor of a WT behind another WT, the wake expands with down-stream distance. The model used here is a Jensen wake model [11]. This model assumed that the wake expands linearly with down-stream distance. The velocity deficit is a loss due to the interaction between two WTs placed one behind the other, In multiple wakes of N turbines, assuming that the kinetic energy deficit of a mixed wake is equal to the sum of the energy deficits [12].

The power generated by the wind farm $P_{w f}$, expressed by equation 1 , is the total power for all the wind turbines in the wind farm.

$$
P_{w f}=\sum_{i=1}^{N} P_{i}
$$

where, $N$ is the number of WT and $P_{i}$ is the power of WT $i$.

The efficiency of the WF is the ratio of the total power produced by the WF to the sum of the power for each individual WT. The efficiency of the farm can be expressed as shown in [13], by equation 2 .

$$
\eta_{w f}=\frac{P_{w f}}{\sum_{i=1}^{N} P_{s i}}
$$

where $P_{s i}$ is the power of WT $i$ if it is functioning as a single turbine.

The AEP (Annual Energy Production) for all wind turbines within wind farm can be calculated using the following expression [14]:

$$
A E P=T \sum_{i=1}^{\text {directions }} \sum_{j=1}^{\text {speed }} \sum_{k=1}^{\text {turbines }} \text { Frequency }_{i j k} \text { Power }_{i j k}
$$

where, Frequency $y_{i j k}$ is the frequency or probability of wind coming from direction $i$, with wind speed $j$ on to the wind turbine $k, T$ is the number of hours in one year $(365 \times 24)$ and Power $_{i j k}$ is the power (in kilowatts) generated by that turbine for the same wind speed and direction .

\subsection{Cost model and objective function}

In this article the objective function will be used, this function serves as a criterion for determining the best arrangement of the WF. The goal is then to minimize this function up to the optimum, this function will be used. As shown by Grady [15]. This objective function is expressed by the following equation 4 .

$$
\text { Objective }=\frac{\operatorname{Cos} t}{p_{w f}}
$$

Where Cost is cost function, which is a non-dimensional function of WTs number $(\mathrm{N})$ given by the equation below. 


$$
\operatorname{Cost}=N\left(\frac{2}{3}+\frac{1}{3} e^{-0.00174 N^{2}}\right)
$$

\section{OPTIMIZATION PROCESS}

We consider $7 \mathrm{~km} \times 5 \mathrm{~km}$ wind farm that is divided into a grid of $(\mathrm{nD} \times \mathrm{mD})$ under 88 configurations $(n=5 . .12, m=5 . .15)$, see Table 3. with the number of wind turbines is between 30 and 176 see Table 4. The search for the optimal configuration of WTs within wind farm (regular layout) is carried out by an iterative approach, the CWD distance remains constant between the wind turbines and the distance PWD varies from $5 \mathrm{D}$ to $15 \mathrm{D}$ then the CWD distance is incremented up to 12D. When the optimal solution is obtained, the number of WTs and the distances separation between wind turbines along CWD and PWD are known. After The large wind farm (LWF) is divided into 4 sub-wind farms (SWF1, SWF2, SWF3, SWF4) area of $2 \mathrm{~km} \times 3 \mathrm{~km}$, a new search for the optimal configuration of WTs within LWF (irregular layout) is achieved by using RCGA, the distance between the 4 sub-wind farms is 12D along CWD and 15D along PWD. To execute our approach, we have developed a MATLAB software code using the RCGA (Real Coded Genetic Algorithm) with 4 subdomains (4 sub wind farms). The output computing results are wind speed, WF power generation, and the cost. The program will be stopped provided that the best fitness stills the same without any change in 400 iterations. The specifications of wind farm parameters are represented in Table 5.

Table 3. Configuration number (CWD-PWD).

\begin{tabular}{lllllllll}
\hline PWD & \multicolumn{2}{l}{ CWD } & & & & & \\
\cline { 2 - 8 } & $5 \mathrm{D}$ & $6 \mathrm{D}$ & $7 \mathrm{D}$ & $8 \mathrm{D}$ & $9 \mathrm{D}$ & $10 \mathrm{D}$ & $11 \mathrm{D}$ & $12 \mathrm{D}$ \\
\hline 5D & 1 & 12 & 23 & 34 & 45 & 56 & 67 & 78 \\
6D & 2 & 13 & 24 & 35 & 46 & 57 & 68 & 79 \\
7D & 3 & 14 & 25 & 36 & 47 & 58 & 69 & 80 \\
8D & 4 & 15 & 26 & 37 & 48 & 59 & 70 & 81 \\
9D & 5 & 16 & 27 & 38 & 49 & 60 & 71 & 82 \\
10D & 6 & 17 & 28 & 39 & 50 & 61 & 72 & 83 \\
11D & 7 & 18 & 29 & 40 & 51 & 62 & 73 & 84 \\
12D & 8 & 19 & 30 & 41 & 52 & 63 & 74 & 85 \\
13D & 9 & 20 & 31 & 42 & 53 & 64 & 75 & 86 \\
14D & 10 & 21 & 32 & 43 & 54 & 65 & 76 & 87 \\
15D & 11 & 22 & 33 & 44 & 55 & 66 & 77 & 88 \\
\hline
\end{tabular}

Table 4. Wind turbines number (CWD-PWD).

\begin{tabular}{|c|c|c|c|c|c|c|c|c|}
\hline \multirow[t]{2}{*}{ PWD } & \multicolumn{8}{|c|}{ CWD } \\
\hline & $5 \mathrm{D}$ & $6 \mathrm{D}$ & $7 \mathrm{D}$ & $8 \mathrm{D}$ & 9D & $10 \mathrm{D}$ & $11 \mathrm{D}$ & $12 \mathrm{D}$ \\
\hline $5 \mathrm{D}$ & 176 & 144 & 128 & 112 & 96 & 96 & 80 & 80 \\
\hline $6 \mathrm{D}$ & 143 & 117 & 104 & 91 & 78 & 78 & 65 & 65 \\
\hline 7D & 121 & 99 & 88 & 77 & 66 & 66 & 55 & 55 \\
\hline $8 D$ & 110 & 90 & 80 & 70 & 60 & 60 & 50 & 50 \\
\hline 9D & 99 & 81 & 72 & 63 & 54 & 54 & 45 & 45 \\
\hline 10D & 88 & 72 & 64 & 56 & 48 & 48 & 40 & 40 \\
\hline $11 \mathrm{D}$ & 77 & 63 & 56 & 49 & 42 & 42 & 35 & 35 \\
\hline $12 \mathrm{D}$ & 77 & 63 & 56 & 49 & 42 & 42 & 35 & 35 \\
\hline $13 \mathrm{D}$ & 66 & 54 & 48 & 42 & 36 & 36 & 30 & 30 \\
\hline $14 \mathrm{D}$ & 66 & 54 & 48 & 42 & 36 & 36 & 30 & 30 \\
\hline $15 \mathrm{D}$ & 66 & 54 & 48 & 42 & 36 & 36 & 30 & 30 \\
\hline
\end{tabular}


Table 5. specifications of wind farm parameters.

\begin{tabular}{ll}
\hline Parameters & Specifications \\
\hline Wind turbine model & SWT-2.3 MW -93 [16] \\
Rated power $(\mathrm{kW})$ & 2300 \\
Hub height of WTs, Z (m) & 80 \\
Wind turbine rotor radius, $\mathrm{Rr}(\mathrm{m})$ & 46.5 \\
Turbine thrust coefficient, $\mathrm{C}_{\mathrm{T}}$ & 0.88 \\
Roughness length of ground, $\mathrm{Z}_{0}(\mathrm{~m})$ & 0.1 \\
The entrainment constant, $\alpha$ & 0.0748 \\
The axial induction factor, $a$ & 0.3268 \\
\hline
\end{tabular}

\section{Results and discussion}

In the present study, 88 configurations of wind farm layout is considered, by varying the spacing between wind turbines along and across the prevailing wind direction, 8 different WTs separations in CWD (5D to 12D) with 11 different WTs separations in PWD (5D to 15D) were allowed to evolve over 88 wind farm layout. After the execution of the program, the best solution for 42 WTs from configuration number 63 (42C63) placement in WF is achieved with a best fitness value of 0.000330009 . The comparison results between the top five best layout of wind farm (42C63, 42C43, 42C44, 40C 83 and 42C42) is presented in Table 6. For 42 WTs from configuration number $63(42 \mathrm{C} 63)$, the total power is $86816.79 \mathrm{~kW}$, the fitness value is 0.000330009 and the efficiency is $89.87 \%$. The best solutions of 42 WTs layout within wind farm are depicted in Figures 12-(a) and 12-(b), the wind turbines numbers and Total power evolution by configuration and by spacing are depicted respectively in Figure 4 and Figure 5.

Table 6. The comparison results between the top five best layout

\begin{tabular}{ccccccc}
\hline $\begin{array}{c}\text { Number } \\
\text { of WTs }\end{array}$ & $\begin{array}{c}\text { Number } \\
\text { of WTs }\end{array}$ & $\begin{array}{c}\text { Total power } \\
(\mathrm{kW})\end{array}$ & Fitness value & $\begin{array}{c}\text { Efficiency } \\
(\%)\end{array}$ & $\begin{array}{c}\text { spacing } \\
(\mathrm{CWD})\end{array}$ & $\begin{array}{c}\text { spacing } \\
\text { (PWD) }\end{array}$ \\
\hline 63 & 42 & 86816.79498 & 0.000330009 & 89.87245857 & $10 \mathrm{D}$ & $12 \mathrm{D}$ \\
43 & 42 & 86613.90335 & 0.000330782 & 89.66242583 & $8 \mathrm{D}$ & $14 \mathrm{D}$ \\
44 & 42 & 86573.65257 & 0.000330936 & 89.62075835 & $8 \mathrm{D}$ & $15 \mathrm{D}$ \\
83 & 40 & 82634.95925 & 0.000332675 & 89.82060788 & $12 \mathrm{D}$ & 10D \\
42 & 42 & 86118.73973 & 0.000332684 & 89.14983409 & $8 \mathrm{D}$ & 13D \\
\hline
\end{tabular}

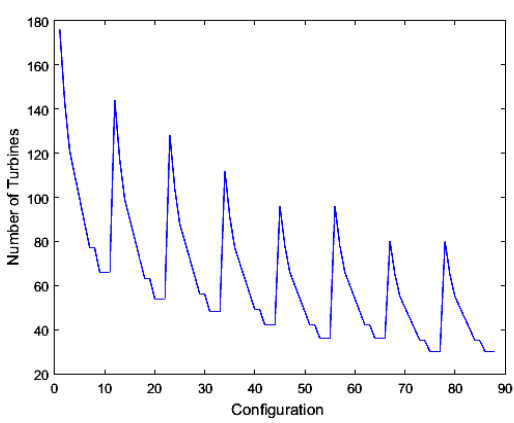

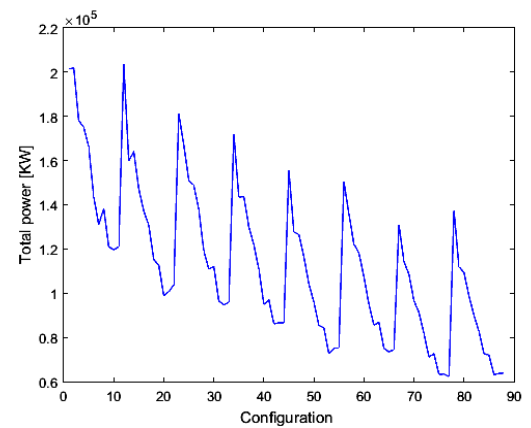

Fig. 4. WT numbers and Total power evolution by configuration: (a) WT numbers evolution;

(b) Total power evolution 


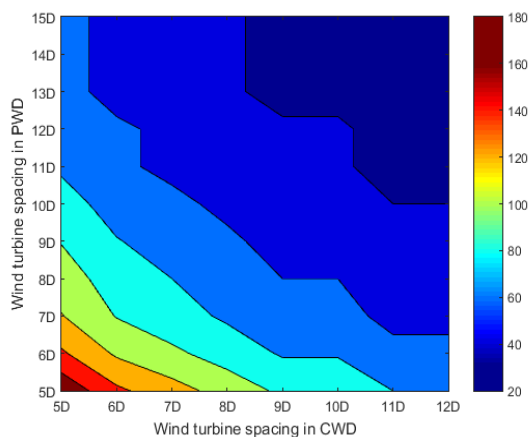

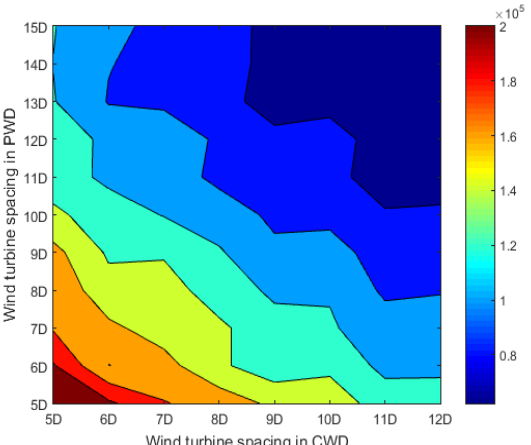

Fig. 5. WT numbers and Total power evolution by spacing: (a) WT numbers evolution; (b) Total power evolution

Fitness and Efficiency evolution by configuration are depicted in Figure 6. Fitness evolution by spacing are depicted in Figure 7-(a). Fitness versus Total power evolution by configuration are depicted in Figure 7-(b). these figures indicate that the best Fitness value corresponding at configuration number 63 with $10 \mathrm{D}$ in CWD and $12 \mathrm{D}$ in PWD.
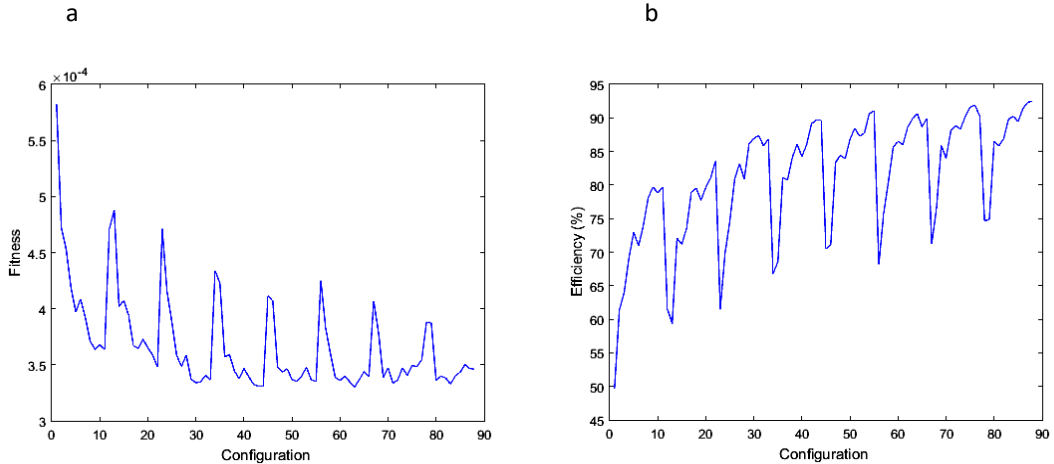

Fig. 6. Fitness and Efficiency evolution by configuration: (a) Fitness evolution; (b) Efficiency evolution

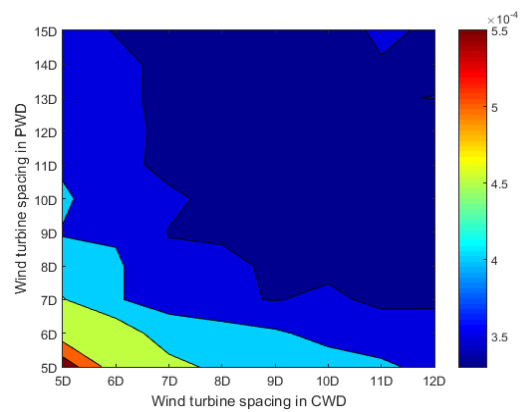

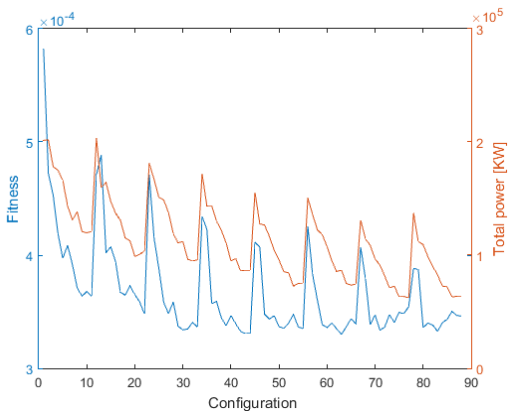

Fig. 7. Fitness versus Total power evolution: (a) Fitness evolution by spacing; (b) Fitness evolution versus Total power evolution by configuration

In the present study, 45 individuals (Probability of crossover value of 0.9, Probability of mutation value of 0.1 ) were allowed to evolve over 1000 iterations. After the execution of the 
RCGA program for 600 iterations, the best solution for 11 WTs placement in SWF and 42 WTs placement in LWF is achieved with a best fitness value of 0,000325853 (42 WTs). For 42 WTs in LWF (irregular layout), the total power is $87924,02 \mathrm{~kW}$, the fitness value is 0,000325853 and the efficiency is $91,018 \%$. The optimized result obtained for 42 WTs (irregular layout) shows that the optimal arrangement for 42 WTs achieved by using RCGA gives a lower fitness value than 42 WTs (regular layout), See Table 6. Moreover, the efficiency evolution, the total power evolution and the fitness evolution of 11 WTs (SWF) and 42 WTs (LWF) over the searching period are depicted respectively in Figure 8, Figure 9 and Figure 10. Figure 11-(b), and Figure 11-(a), shows respectively the optimal layouts of SWF and LWF (irregular layout).

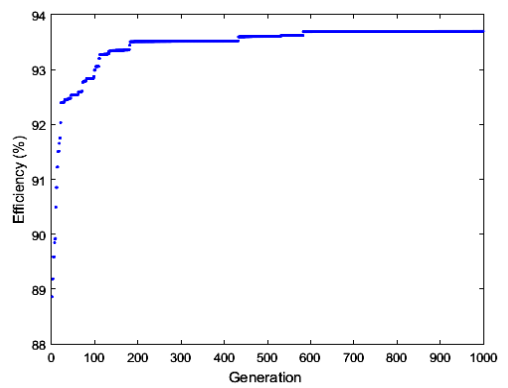

b

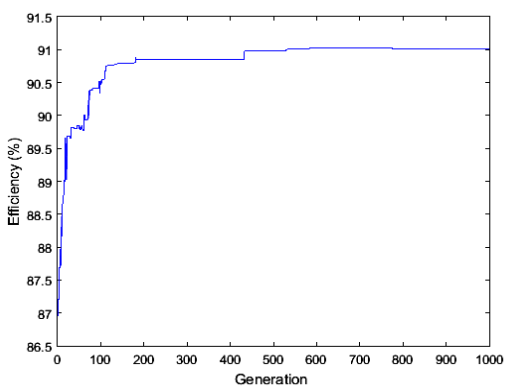

Fig. 8. Efficiency evolution (SWF vs LWF): (a) Efficiency evolution of 11 WTs; (b) Efficiency evolution of 42 WTs.

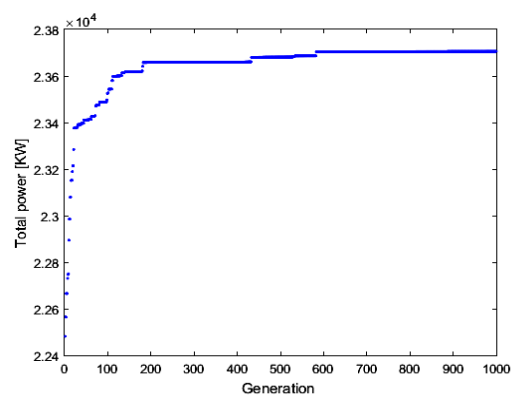

b

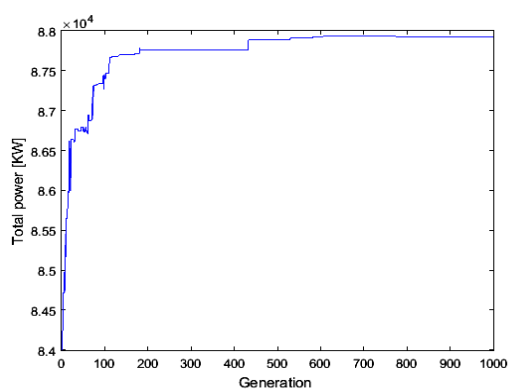

Fig. 9. Total power evolution (SWF vs LWF): (a) Total power evolution of 11 WTs. ; (b) Total power evolution of 42 WTs.

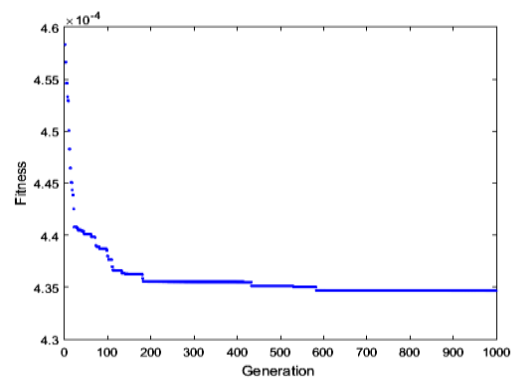

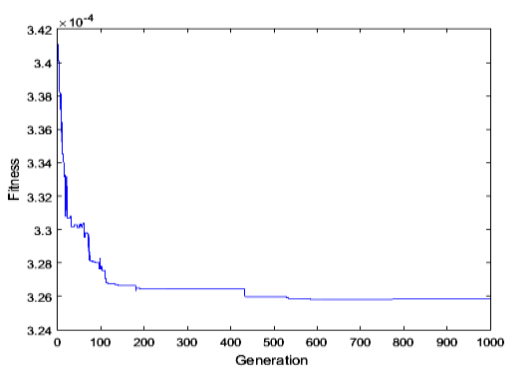

Fig. 10. Fitness evolution (SWF vs LWF): (a) Fitness evolution of 11 WTs; (b) Fitness evolution of 42 WTs 
a

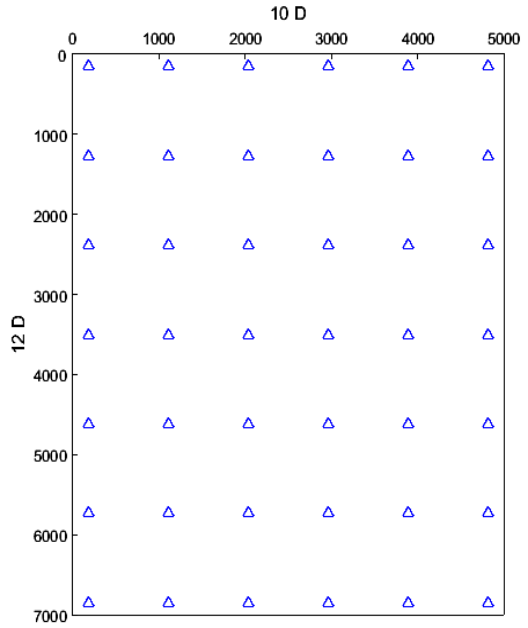

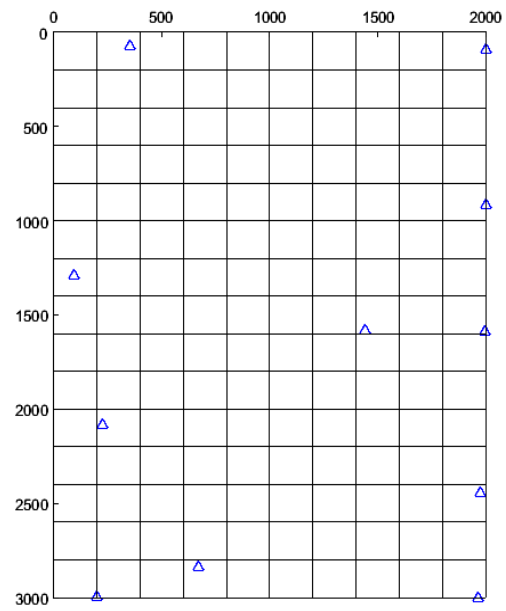

Fig. 11. Wind farm layouts: (a) optimal layout of large wind farm (42 WTs, regular layout) ; (b) optimal layout of Sub wind farm1 (11 WTs, irregular layout) .

a

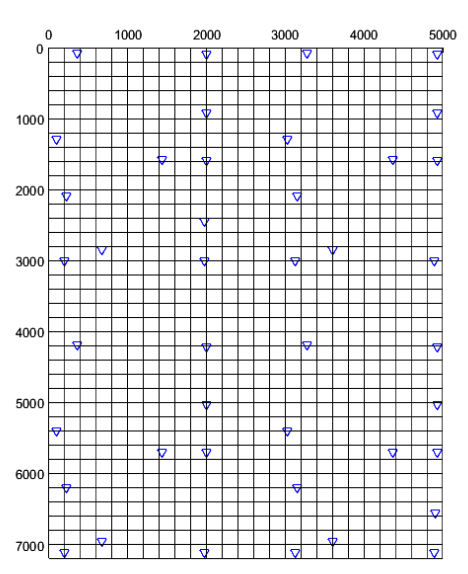

b

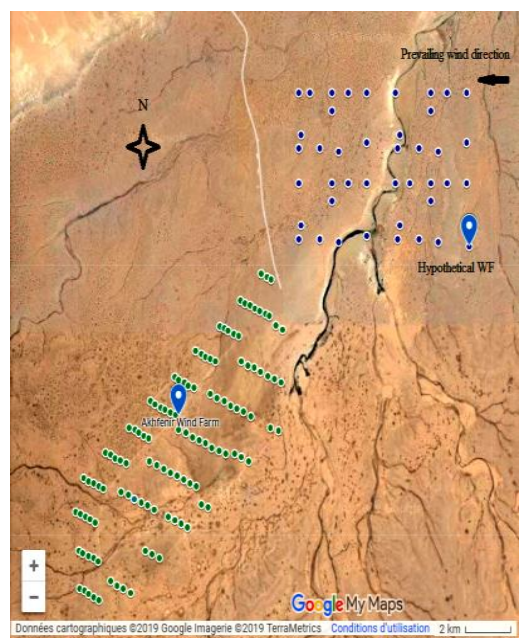

Fig. 12. Wind farm layouts: (a) optimal layout of large wind farm (42 WTs, irregular layout) ; (b) GoogleMyMaps: Optimal layout of hypothetical wind farm (placed perpendicular to prevailing wind direction). 


\section{Conclusions}

In this article, we investigated regular layout and irregular layout of wind turbines within a large wind farm, we have proposed and applied a new approach based on the division of the large wind farm in the sub domain (Sub wind farm), and we have applied real coded genetic algorithm (RCGA) approach to achieve the best placement of WTs in order to get the most out of the power production. The carried out results from Matlab Software showed that the proposed approach is promising in terms of the applicability in large wind farm. It is also more suitable when performing the wind farm layout assessment in WPP (Wind Power Project). In the ongoing research, we will take into consideration the real wind condition of the WFs by using the more complex wake model .

\section{References}

[1] Barthelmie, R. et al.: Modelling and measuring flow and wind turbine wakes in large wind farms offshore. Wind Energy. 12, 5, 431-444 (2009).

[2] Mosetti, G. et al.: Optimization of wind turbine positioning in large windfarms by means of a genetic algorithm. Journal of Wind Engineering and Industrial Aerodynamics. 51, 1, 105-116 (1994).

[3] Archer, C. et al.: Quantifying the sensitivity of wind farm performance to array layout options using large-eddy simulation. Geophysical Research Letters. 40, 18, 4963-4970 (2013).

[4] Gao, X. et al.: Investigation into the optimal wind turbine layout patterns for a Hong Kong offshore wind farm. Energy. 73, 430-442 (2014).

[5] García, L. et al.: Experiments in the wind turbine far wake for the evaluation of an analytical wake model. Journal of Physics: Conference Series. 854, 012015 (2017).

[6] Tremeac, B., Meunier, F.: Life cycle analysis of 4.5MW and 250W wind turbines. Renewable and Sustainable Energy Reviews. 13, 8, 2104-2110 (2009).

[7] "Modern-Era Retrospective analysis for Research and Applications, Version 2" https://gmao.gsfc.nasa.gov/reanalysis/MERRA-2/. [Accessed: 12- Dec- 2018].

[8] "Data Collections"

https://disc. sci.gsfc.nasa.gov/datasets?keywords=\%22MERRA-

2\%22\&page $=1 \&$ source=Models\%2FAnalyses\%20MERRA-2. [Accessed: 12- Dec- 2018].

[9] Deaves, D., Lines, I.: On the fitting of low mean windspeed data to the Weibull distribution. Journal of Wind Engineering and Industrial Aerodynamics. 66, 3, 169-178 (1997).

[10] Lun, I., Lam, J.: A study of Weibull parameters using long-term wind observations. Renewable Energy. 20, 2, 145-153 (2000).

[11] N. O., Jensen.: A note on wind generator interaction. Roskilde, Denmark: Risø National Laboratory. November (1983).

[12] Katić, I., J, Højstrup, J., Jensen, N.: A simple model for cluster efficiency. European wind energy association conference and exhibition. October (1986).

[13] Chowdhury, S. et al.: Unrestricted wind farm layout optimization (UWFLO): Investigating key factors influencing the maximum power generation. Renewable Energy. 38, 1, 16-30 (2012).

[14] Mittal, P. et al.: A novel hybrid optimization methodology to optimize the total number and placement of wind turbines. Renewable Energy. 86, 133-147 (2016).

[15] Grady, S. et al.: Placement of wind turbines using genetic algorithms. Renewable Energy. 30, 2, 259-270 (2005).

[16] "SWT-2.3-93 (Siemens)"

https://www.thewindpower.net/turbine_en_22_siemens_swt-2.3-93.php. [Accessed: 01- Dec- 2018]. 